\title{
Aldehyde dehydrogenase
}

\section{Covalent intermediate in aldehyde dehydrogenation and ester hydrolysis}

\author{
Erich E. BLATTER, Darryl P. ABRIOLA and Regina PIETRUSZKO* \\ Center of Alcohol Studies, Rutgers University, Piscataway, NJ 08855-0969, U.S.A.
}

\begin{abstract}
4-trans-( $N N$-Dimethylamino)cinnamaldehyde (an aldehyde, DACA) and 4-trans-( $N N$-dimethylamino)cinnamoylimidazole (an amide, DACI) have been shown to be substrates for human aldehyde dehydrogenase (EC 1.2.1.3) which form chromophoric covalent intermediates. The spectra of covalent intermediates from both the cytoplasmic (E1) and mitochondrial (E2) isoenzymes derived from DACA and DACI were compared. The spectra were similar when either substrate was used, and also when the two isoenzymes were compared, and resembled that obtained for 4-trans-( $N N$ dimethylamino)cinnamoyl- $N$-acetylcysteine, but differed from the spectrum of 4-trans-( $N N$-dimethylamino)cinnamoyl ethyl ester. After extensive digestion of the covalent intermediates from both ${ }^{3} \mathrm{H}$-labelled DACA and DACI with Pronase and purification, the labelled amino acid was identified as cysteine. Covalent intermediates from both DACA and DACI were also digested with trypsin, and labelled peptides were purified by ion-exchange and reverse-phase chromatography. Amino acid sequence analysis showed that the peptide comprising residues 273-307 was labelled by both DACA and DACI. The radioactive label at cysteine residues 301-303 of the primary structure could be unequivocally identified by employing the DACA derivative. Assignment of label to cysteine- 302 was achieved by employing iodoacetamide-labelled E1 isoenzyme (iodoacetamide specifically labels cysteine-302), in which case there was no formation of the covalent intermediate from either DACA or DACI. In addition, cysteine-302 is the only cysteine residue conserved in all aldehyde dehydrogenases sequenced. Thus cysteine-302 is the amino acid residue that forms a covalent intermediate with both aldehyde and ester substrates.
\end{abstract}

\section{INTRODUCTION}

Aldehyde dehydrogenase (EC 1.2.1.3) catalyses dehydrogenation of aldehydes and hydrolysis of esters via a covalent intermediate, which was postulated to be a thioester (Jakoby, 1963). Human aldehyde dehydrogenase isoenzymes E1 and E2 were first purified in our laboratory in 1977 (Greenfield \& Pietruszko, 1977); in the 1980s both isoenzymes were sequenced (Hempel et al., 1984, 1985). Chemical modification with iodoacetamide identified a super-reactive cysteine residue, later found to be residue 302 , in a complete amino acid sequence (Hempel, 1981 ; Hempel \& Pietruszko, 1981 ; Hempel et al., 1982a; Hempel et al., 1984, 1985). Since total inactivation was not achieved (Hempel \& Pietruszko, 1981), cysteine-302 could not be unequivocally assigned to the active site. The use of coenzyme analogues determined cysteine-369 and -302 to be near the coenzyme-binding site (von Bahr-Lindstrom et al., 1985). Chemical modification work with $N$-ethylmaleimide claimed to have identified cysteine- 49 and -162 as part of the active site of aldehyde dehydrogenase (Tu \& Weiner, 1988a,b). Our laboratory developed an aldehyde substrate-based affinity reagent, bromoacetophenone (MacKerell et al., 1986), and used it to identify glutamate-268 (Abriola et al., 1987). Bromoacetophenone also labelled cysteine-302 (Abriola et al., 1990), and in conjunction with another study employing a vinyl ketone affinity reagent (Blatter et al., 1990), assignment of cysteine-302 to the active site could finally be made.

The above work, however, could not resolve the issue of residue functionality. It was proposed that aldehyde dehydrogenase mechanism involved acylation of a different group from that involved in hydrolysis of esters (Kitson, 1978; MacGibbon et al., 1978; Deady et al., 1985). Tu \& Weiner $(1988 a, b)$ concluded that aldehyde dehydrogenation proceeded at cysteine- 49 , whereas ester hydrolysis proceeded at cysteine-162. Duncan (1985) has argued for a single-site model; other evidence in support of a single-site model includes reports of reversal of the reaction to produce acetaldehyde from 4-nitrophenyl acetate and NADH (Duncan, 1979; Loomes \& Kitson, 1986). Loomes et al. (1990), employing the aldehyde substrate 4-trans-( $N N$-dimethylamino) cinnamaldehyde (DACA), proposed serine- 74 as a candidate for the catalytic residue for aldehyde dehydrogenation, whereas Kitson et al. (1991) identified cysteine-302 as the catalytic residue for ester hydrolysis.

The 4-trans-( $N N$-dimethylamino)cinnamoyl derivatives are highly chromophoric and were previously employed in studies of elastase catalysis (Breaux \& Bender, 1976) as well as those of chymotrypsin and carboxypeptidase A (Hoffman et al., 1983; Weber et al., 1986). In addition to work by Loomes et al. (1990), DACA was used with sheep liver aldehyde dehydrogenase in rapid kinetic studies which resulted in observation of a transient reaction intermediate (Buckley \& Dunn, 1982, 1985). Since the acyl group from DACA and 4-trans-( $N N$-dimethylamino)cinnamoylimidazole (DACI) should be identical, identical covalent intermediates would be expected only if the same enzyme residue were involved in their formation. Thus, DACA and DACI, which were ${ }^{3} \mathrm{H}$-labelled for the present study, had a major advantage over chemical-modification reagents or even site-directed mutagenesis in their ability to assign functionality to an amino acid residue. Identification of the amino acid residue involved in formation of the covalent intermediate with DACA and DACI is presented here.

Abbreviations used: DACA, 4-trans-( $N N$-dimethylamino)cinnamaldehyde; DACI, 4-trans-(NN-dimethylamino)cinnamoylimidazole; TFA, trifluoroacetic acid.

* To whom correspondence should be addressed. 


\section{MATERIALS AND METHODS}

\section{Materials}

Iodoacetic acid, DACA, 2-mercaptoethanol, guanidinium chloride, trichloroacetic acid, imidazole, $N$-acetylcysteine, Trizma base and silica gel (70-230 mesh; $6 \mathrm{~nm}$ pore size) were from Sigma. Iodoacetic acid and DACA were recrystallized from light petroleum (b.p. $35-60^{\circ} \mathrm{C}$ ) and $50 \%(\mathrm{v} / \mathrm{v}$, in water) ethanol respectively. $\mathrm{NAD}^{+}$(grade I) and Pronase were from Boehringer Mannheim. H.p.l.c.-grade acetonitrile, ethyl acetate and methanol were from Fisher Scientific. H.p.l.c.-grade benzene, 4-trans-( $N N$-dimethylamino)cinnamic acid, $N N$-dicyclohexylcarbodi-imide and anhydrous tetrahydrofuran were from Aldrich. $N$-tosyl-L-phenylalanylchloromethane ('TPCK')-treated trypsin was from Worthington Biochemical Corp. Spectro-grade trifluoroacetic acid (TFA) was from Pierce. H.p.l.c. columns were obtained from Supelco and Waters; Superose 12 and Mono P columns were from Pharmacia. ${ }^{3} \mathrm{H}$-exchange labelling of DACA was performed by the du Pont-NEN Research Products Tritium Labelling Laboratory. Solvents for amino-acid-composition analysis were Sequenal grade, from Pierce, and amino acid standards were from Pierce, Sigma or Aldrich. T.l.c. plates used included Adsorbosil RP high-performance t.l.c. plates $(10 \mathrm{~cm} \times 10 \mathrm{~cm})$ and Macherey-Nagel Polygram Sil G $(20 \mathrm{~cm} \times 20 \mathrm{~cm})$ from Alltech, 13181 silica gel with fluorescent indicator $(20 \mathrm{~cm} \times 20 \mathrm{~cm})$ from Kodak, and Uniplate silica gel $\mathrm{H}$ $(250 \mu)$ from Analtech.

\section{Enzyme preparation and kinetic measurements}

The E1 and E2 isoenzymes were purified to homogeneity as described by Hempel et al. (1982b). Homogeneity was confirmed by isoelectric focusing and specific activity. Before use, the enzymes were subjected to gel filtration employing a Sephadex G-50 (fine grade) column $(1.7 \mathrm{~cm} \times 20 \mathrm{~cm})$ equilibrated in sodium phosphate buffer ( $30 \mathrm{~mm}$, pH 7.0, containing 1 mM-EDTA). Standard esterase and dehydrogenase activity assays and protein determinations were done as previously described (Abriola et al., 1990).

\section{Purification of [ $\left.{ }^{3} \mathrm{H}\right] \mathrm{DACA}$}

[ ${ }^{3} \mathrm{H}$ ]DACA was purified by using a Waters $\mathrm{C}_{18}$ column with a 40 min linear gradient from aq. $0.1 \%(\mathrm{v} / \mathrm{v})$ TFA to methanol, followed by chromatography on a $5 \mu$ Supelco $\mathrm{C}_{18}$ column and the same gradient, yielding $\left[{ }^{3} \mathrm{H}\right] \mathrm{DACA}$ that was greater than $90 \%$ pure (specific radioactivity $\sim 0.1 \mathrm{Ci} / \mathrm{mmol}$ ). An alternative purification procedure employed two-dimensional t.l.c. [hexane/ ethyl acetate $(3: 2, \mathrm{v} / \mathrm{v})$ and benzene/methanol $(19: 1, \mathrm{v} / \mathrm{v})$ as eluents]. Purity of $\left[{ }^{3} \mathrm{H}\right]$ DACA from ${ }^{3} \mathrm{H}$ exchange by New England Nuclear was determined by t.l.c. on Macherey-Nagel Polygram Sil $\mathrm{G}$ thin-layer plates [eluent: hexane/ethyl acetate $(3: 2, \mathrm{v} / \mathrm{v})$ ]. After purification, a known amount of $\left[{ }^{3} \mathrm{H}\right] \mathrm{DACA}$ was dried under $\mathrm{N}_{2}$; unlabelled DACA, dissolved in $50 \%(\mathrm{v} / \mathrm{v})$ ethanol, was added to the $\left[{ }^{3} \mathrm{H}\right] \mathrm{DACA}$ to give a final specific radioactivity of $30000-70000$ c.p.m. $/ \mathrm{nmol}$. The concentration of the $\left[{ }^{3} \mathrm{H}\right]$ DACA stock solution was determined spectrophotometrically by using an absorption coefficient of $29500 \mathrm{M}^{-1} \cdot \mathrm{cm}^{-1}$ at $396 \mathrm{~nm}$ in $30 \mathrm{~mm}$-sodium phosphate buffer, $\mathrm{pH} 7.0$, containing 1 mM-EDTA.

\section{Synthesis of 4-trans-( $N N$-dimethylamino)cinnamoyl derivatives}

4-trans-( $N N$-Dimethylamino)cinnamoyl- $N$-acetylcysteine was prepared by the method of Grunwell \& Foerst (1976); unlabelled DACI was prepared by the method of Breaux \& Bender (1976; m.p. $\left.163-167^{\circ} \mathrm{C}\right)$; 4-trans-( $N N$-dimethylamino) cinnamoyl ethyl ester was prepared as described by Pfeiffer \& Haefelin (1922; m.p. $\left.74.5-75^{\circ} \mathrm{C}\right)$.

\section{Synthesis of $\left[{ }^{3} \mathrm{H}\right] \mathrm{DACI}$}

[ $\left.{ }^{3} \mathrm{H}\right]$ DACA (specific radioactivity, $0.1 \mathrm{Ci} / \mathrm{mmol}$ ) was oxidized to $\left[{ }^{3} \mathrm{H}\right]$ 4-trans-( $N N$-dimethylamino) cinnamic acid by incubation with the E2 enzyme $(4.5 \mu \mathrm{M})$ and $\mathrm{NAD}^{+}(6.9 \mathrm{mM})$ in $0.1 \mathrm{M}-$ sodium pyrophosphate buffer, $\mathrm{pH} 9.0$, containing $1.0 \mathrm{~mm}$ EDTA, for $40 \mathrm{~h}$ at room temperature. The reaction mixture was extracted with $10 \mathrm{vol}$. of methylene chloride. The organic phase was dried under vacuum, re-dissolved in a minimal volume of tetrahydrofuran, applied to t.l.c. plates (Macherey-Nagel; $10 \mathrm{~cm} \times 10 \mathrm{~cm})$, and developed with benzene/methanol $(19: 1$, $\mathrm{v} / \mathrm{v}) .\left[{ }^{3} \mathrm{H}\right] 4-$ trans-( $N N$-Dimethylamino)cinnamic acid, showing a blue fluorescence under u.v. light, was eluted with tetrahydrofuran, evaporated to less than $100 \mu \mathrm{l}$, and added to 4-trans( $N N$-dimethylamino)cinnamic acid and imidazole under conditions identical with those used to synthesize unlabelled DACI. $\left[{ }^{3} \mathrm{H}\right] \mathrm{DACI}$ was purified by t.l.c. alone; yields were not sufficient for recrystallization. The specific radioactivity of DACI (6000 c.p.m./nmol) was determined after t.l.c. by counting an aliquot for radioactivity and determining the concentration by its absorbance at $425 \mathrm{~nm}$ (absorption coefficient $25.2 \mathrm{mM}^{-1} \cdot \mathrm{cm}^{-1}$; Breaux \& Bender, 1976).

\section{Preparation of enzyme intermediate and determination of absorption spectra}

The E1 and E2 isoenzymes (4-10 $\mu \mathrm{M})$ were each incubated with DACA $(80-250 \mu \mathrm{M})$ in the presence or absence of $\mathrm{NAD}^{+}$ (1-3 mM) or with DACI $(50-100 \mu \mathrm{M})$ in sodium phosphate buffer (30-50 mM), pH 7.0, containing EDTA (1 mM). After 60-120 s at $25^{\circ} \mathrm{C}$, the protein was precipitated by the addition of an equal volume of $10 \%(w / v)$ trichloroacetic acid. After centrifugation and washing, the samples were dissolved in an appropriate buffer. U.v.-visible spectra were obtained on a Shimadzu UV-260 u.v.-visible recording spectrophotometer, with the same buffer in the reference cell. All $\lambda_{\text {max. }}$ values reported are averages for at least two scans.

\section{Carboxymethylation and tryptic hydrolysis}

Carboxymethylation and tryptic digestion were performed by the method of Hempel \& Pietruszko (1981) without prior reduction, since the labelled enzyme was unstable in 2-mercaptoethanol and dithiothreitol (Blatter, 1990).

\section{Purification of DACA- or DACI-labelled tryptic peptides by f.p.l.c.}

The freeze-dried tryptic hydrolysate was dissolved in $5 \mathrm{~mm}$ potassium phosphate buffer, $\mathrm{pH} 6.5$, and applied to a Pharmacia Mono $\mathrm{P}$ column which had been equilibrated in this buffer. The column was washed for about $25 \mathrm{~min}$ (with a flow rate of $0.5 \mathrm{ml} / \mathrm{min}$ ) with the same buffer, before initiation of a $40 \mathrm{~min}$ linear gradient to $1 \mathrm{M}-\mathrm{KCl}$ in $5 \mathrm{~mm}$-potassium phosphate buffer, $\mathrm{pH}$ 6.5. Upon completion of the gradient, the radioactive material was eluted with acetic acid (1-2 $\mathrm{M})$ or guanidinium chloride (3-6 M). After elution with acetic acid, $\mathrm{pH}$ adjustment was made by using ammonium hydroxide; the labelled peptide precipitated during $\mathrm{pH}$ adjustment.

\section{Purification of DACI-labelled E2 tryptic peptides}

Fractions containing radioactivity were scanned for u.v.visible absorbance. After $\mathrm{pH}$ adjustment to $\mathrm{pH}$ 6.5-7.0, the precipitate was collected, dissolved in $1 \mathrm{M}$-acetic acid and applied to a $\mathrm{C}_{18} \mu$ Bondapak column and eluted with a gradient from $0.1 \%$ TFA to $100 \%$ acetonitrile $(80 \mathrm{~min}$, linear gradient; flow rate: $1 \mathrm{ml} / \mathrm{min}$ ). Further purification employed a diphenylbonded reverse-phase column and a gradient of $0.1 \%$ TFA to $50 \%$ acetonitrile ( $80 \mathrm{~min}$, curved gradient, with a flow of 
Table 1. Comparison of Michaelis $\left(K_{\mathrm{m}}\right)$ and catalytic rate constants $\left(\boldsymbol{k}_{\text {cat }}\right)$ of the $\mathrm{E} 1$ and $\mathrm{E} 2$ isoenzymes with propanal, $p$-nitrophenyl acetate, DACA and DACl as substrates at $\mathrm{pH} 7.0$

Conditions were as follows: for determinations of kinetic constants with aldehyde substrates, E1 (238 nM) or E2 (322 nM) was assayed at $340 \mathrm{~nm}$ and $25^{\circ} \mathrm{C}$ with $0.5 \mathrm{mM}-\mathrm{NAD}^{+}$and 9-28 $\mu \mathrm{M}$-DACA in $30 \mathrm{~mm}$-sodium phosphate containing $1 \mathrm{~mm}$-EDTA at pH $7.0\left(\epsilon_{\mathrm{NADH}} 6220 \mathrm{~m}^{-1} \cdot \mathrm{cm}^{-1}\right)$. For esterase substrates the same buffer was used. Assays were done at enzyme concentrations of $0.04-0.18 \mu \mathrm{M}$ and substrate concentrations of $0.1-10.0 \mu \mathrm{M}$, at $25^{\circ} \mathrm{C}$ and at $425 \mathrm{~nm}$ for DACI and $400 \mathrm{~nm}$ for $p$-nitrophenyl acetate (pNPA) $\left(\epsilon_{\mathrm{DACl}} 25200 \mathrm{M}^{-1} \cdot \mathrm{cm}^{-1} ; \epsilon_{\mathrm{m}}\right.$ $\left.9800 \mathrm{~m}^{-1} \cdot \mathrm{cm}^{-1}\right)$. Where several values were obtained, individual values and means are presented. Michaelis constants and maximal velocities were determined by the method of Yun \& Suelter (1977) at $25^{\circ} \mathrm{C}$. Catalytic rate constants were obtained by adjusting maximal velocities to optimum enzyme activity: $0.6 \mu \mathrm{mol} / \mathrm{min}$ per $\mathrm{mg}$ for the $\mathrm{E} 1$ isoenzyme and $1.6 \mu \mathrm{mol} / \mathrm{min}$ per $\mathrm{mg}$ for the E2 isoenzyme, in the standard assay system.

\begin{tabular}{|c|c|c|c|c|c|c|}
\hline Isoenzyme & Substrate & $K_{\mathrm{m}}(\mu \mathrm{M})$ & Mean & $k_{\text {eat. }}(\mu \mathrm{mol} / \mathrm{min}$ per $\mathrm{mg})$ & Mean & $k_{\text {cat. }} / K_{\mathrm{m}}$ \\
\hline & Aldehydes & & & & & \\
\hline \multirow[t]{2}{*}{ El } & DACA & $1.2,5.0$ & 3.1 & $0.04, \quad 0.03$ & 0.04 & 0.01 \\
\hline & Propanal & 4.6 & 4.6 & 0.5 & 0.5 & 0.11 \\
\hline \multirow[t]{3}{*}{ E2 } & DACA & $0.2,0.4$ & 0.3 & $0.03, \quad 0.03$ & 0.03 & 0.1 \\
\hline & Propanal & $1.0,0.8$ & 0.9 & $0.2, \quad 0.3$ & 0.25 & 0.28 \\
\hline & Esters and amides & & & & & \\
\hline \multirow[t]{2}{*}{ El } & DACI & $0.8,0.8$ & 0.8 & $0.002,0.004$ & 0.003 & 0.004 \\
\hline & pNPA & $0.4,0.4,2.6$ & 1.1 & $0.08, \quad 0.09,0.12$ & 0.1 & 0.09 \\
\hline \multirow[t]{2}{*}{ E2 } & DACI & $0.2,0.6$ & 0.4 & $0.01, \quad 0.02$ & 0.02 & 0.05 \\
\hline & pNPA & $2.3,0.3$ & 1.3 & $0.22, \quad 0.23$ & 0.22 & 0.17 \\
\hline
\end{tabular}

$2 \mathrm{ml} / \mathrm{min})$; the radioactive material separated into two peaks (fractions $12.5-14.0$, containing $54 \%$ of the total radioactivity, and fractions $15.0-17.5$, with $46 \%$ of the total radioactivity).

(i) Purification of DACI-labelled peptide from fractions 12.5-14.0. Material from these fractions was chromatographed on a Supelco $\mathrm{C}_{4}$ (butyldimethyl) column, with a gradient of $0.1 \%$ TFA to $50 \%$ acetonitrile $(80 \mathrm{~min}$, linear gradient, flow of $3 \mathrm{ml} / \mathrm{min}$ ). The final two steps of purification involved chromatography on the diphenyl-bonded column, using first a gradient of $0.1 \%$ TFA to $100 \%$ acetonitrile ( $40 \mathrm{~min}$, linear gradient, flow of $2 \mathrm{ml} / \mathrm{min}$ ) and finally a gradient of $0.1 \%$ TFA to $100 \%$ methanol (40 min, linear gradient, with a flow rate of $3 \mathrm{ml} / \mathrm{min}$ ).

(ii) Purification of DACI-labelled peptide from fractions 15.0-17.5. This peptide was further purified using the $\mathrm{C}_{4}$ column and a gradient of $0.1 \%$ TFA to $100 \%$ acetonitrile $(40 \mathrm{~min}$, linear gradient, with a flow rate of $2.5 \mathrm{ml} / \mathrm{min}$ ). The final chromatographic step employed the diphenyl-bonded column and a gradient of $0.1 \%$ TFA to $50 \%$ acetonitrile (40 min, linear gradient, flow of $2 \mathrm{ml} / \mathrm{min}$ ).

\section{$N$-Terminal sequencing and amino acid analysis}

$N$-Terminal sequencing was performed at the New York Blood Center, Laboratory of Microchemistry, as described by Abriola et al. (1990). The initial yields of individual peptides were determined by extrapolating the repetitive yields of all component amino acids to zero time. Spurious assignment of peptide initial yields due to anomalously low or high levels of an amino acid in the initial sequencing cycles could therefore be avoided. When purification of the label-bearing peptide was only partial, sequence analysis resulted in multiple simultaneous sequences. These multiple sequences could be followed with some degree of reliability when different peptides occurred in different amounts; their identification was made easier by the availability of complete primary structures (Hempel et al., 1984, 1985). Amino-acid-composition analysis was by the methods of Liu \& Boykins (1989) and Heinrikson \& Meredith (1984).

\section{RESULTS}

\section{DACA and DACI as substrates for aldehyde dehydrogenase}

DACA was tested as a substrate for the E1 and E2 isoenzymes at $\mathrm{pH}$ 7.0. In Table 1 , the $K_{\mathrm{m}}$ and $k_{\text {cat. }}$ values and $k_{\text {eat. }} / K_{\mathrm{m}}$ ratios are compared with those for propanal (which is a good substrate for both isoenzymes). Although $K_{\mathrm{m}}$ values for DACA and propanal are similar in magnitude, DACA is oxidized by the E2 isoenzyme at one-eighth the rate of propanal oxidation, and the rate of oxidation of DACA by the E1 isoenzyme is one-fourteenth that of propanal. Comparison of $k_{\text {cat. }} / K_{\mathrm{m}}$ ratios show that DACA is a relatively good substrate for the E2 isoenzyme, but worse than propanal for the $\mathrm{E} 1$ isoenzyme. $K_{\mathrm{m}}$ and $k_{\text {cat. }}$ values were also determined for the E1 and E2 isoenzymes with both DACI (which is an amide) and 4-nitrophenyl acetate as substrates (Table 1). The $K_{\mathrm{m}}$ values for DACI are similar to those of 4nitrophenyl acetate, but the $k_{\text {cat. }}$ values are again considerably lower (one order of magnitude). Thus the ratio of $k_{\text {cat. }} / K_{\mathrm{m}}$ is lower with DACI ; like DACA, DACI is a better substrate for the $\mathrm{E} 2$ isoenzyme than for the $\mathrm{E} 1$ isoenzyme.

\section{Effects of chloral hydrate and $\mathrm{NAD}^{+}$on the formation of covalent intermediates}

The intermediates formed by incubation of the E1 and E2 isoenzymes with DACA in the presence of $\mathrm{NAD}^{+}$or DACI in the presence or absence of $\mathrm{NAD}^{+}$were yellow in colour and gave characteristic spectra (Fig. 1). Controls incubated in the absence of DACA or DACI or with DACA in the absence of NAD ${ }^{+}$were white.

To test the effect of a competitive inhibitor on the formation of covalent intermediate, both $\mathrm{NAD}^{+}$and chloral hydrate were employed. Within the time period of the experiment, very little of the intermediate was formed when chloral hydrate was present, showing that chloral hydrate effectively protected against formation of covalent intermediate from DACA (Fig. 1a); analogous results were obtained with DACI as substrate (Fig. 1b). The intermediate formed from DACI in the absence of $\mathrm{NAD}^{+}$is included as control. Protection by chloral hydrate against DACI was almost total.

\section{Stoichiometry of incorporation of DACA or DACI into aldehyde dehydrogenase}

Stoichiometry of incorporation was determined from the absorption coefficient of the intermediate and from the incorporated ${ }^{3} \mathrm{H}$ label. This stoichiometry was variable at first and ranged between 0.3 and 2.5 molecules incorporated per molecule of enzyme. Closer examination revealed that incorporation was 


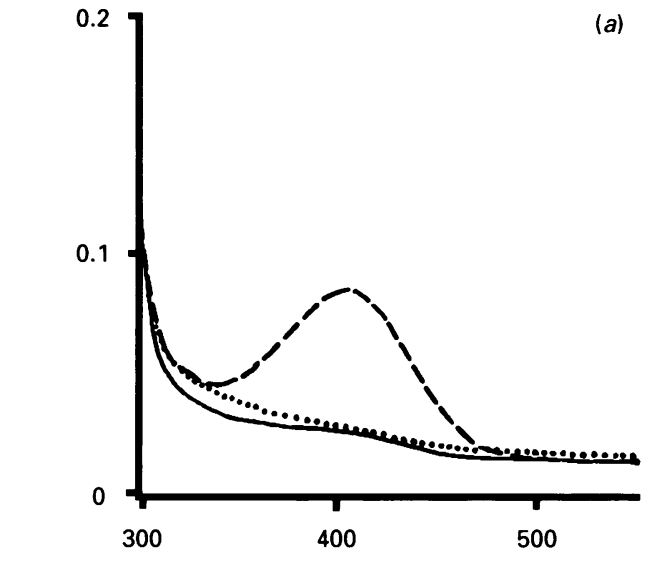

A

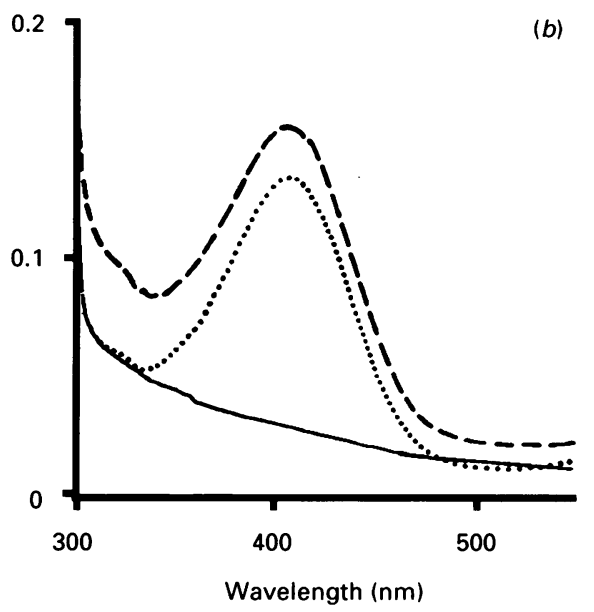

Fig. 1. Effect of chloral hydrate on formation of covalent intermediate from E2 isoenzyme with DACA and DACI

(a) Effect of chloral hydrate on formation of the covalent intermediate from DACA. DACA was incubated at $24^{\circ} \mathrm{C}$ for $100 \mathrm{~s}$ with the $\mathrm{E} 2$ isoenzyme before precipitation with trichloroacetic acid. - , E2 isoenzyme $(1 \mathrm{mg} / \mathrm{ml})+$ DACA $(50 \mu \mathrm{M})+$ chloral hydrate $(50 \mathrm{~mm})+\mathrm{NAD}^{+}(2.5 \mathrm{~mm}) ; \cdots \cdots \quad$ E2 isoenzyme $(1 \mathrm{mg} / \mathrm{ml})$ + DACA $(50 \mu \mathrm{M}) ;----$ E2 $(1 \mathrm{mg} / \mathrm{ml})+$ DACA $(50 \mu \mathrm{M})+\mathrm{NAD}^{+}$ $(2.5 \mathrm{~mm}) .(b)$ Effect of chloral hydrate on the formation of the covalent intermediate from DACI. DACI was incubated at $24{ }^{\circ} \mathrm{C}$ for $100 \mathrm{~s}$ with the E2 isoenzyme before precipitation with trichloroacetic acid. —, E2 isoenzyme $(0.5 \mathrm{mg} / \mathrm{ml})+$ DACI $(55 \mu \mathrm{M})+$ chloral hydrate $(55 \mathrm{mM})+\mathrm{NAD}^{+} \quad(2.5 \mathrm{mM}) ; \quad \cdots \ldots$, E2 isoenzyme $(0.5 \mathrm{mg} / \mathrm{ml})+$ DACI $(55 \mu \mathrm{M}) ;---, \quad$ E2 $(0.5 \mathrm{mg} / \mathrm{ml})+$ DACI $(55 \mu \mathrm{M})+\mathrm{NAD}^{+}(2.5 \mathrm{~mm})$. The precipitate was washed and redissolved in $50 \mathrm{~mm}$-sodium acetate, $\mathrm{pH} 5.2$, containing $2.0 \%$ SDS. Scans were all versus buffer alone in the reference cell. The specific activity of the $\mathrm{E} 2$ isoenzyme was $0.7 \mu \mathrm{mol} / \mathrm{min}$ per $\mathrm{mg}$.

directly proportional to the amount of active enzyme and also that the concentration of substrate and length of incubation were important. Thus, when DACA or DACI were employed at saturating concentrations (e.g. $100 \times K_{\mathrm{m}}$ ), followed by a short incubation the stoichiometry of incorporation corresponded to two molecules of 4-trans-( $N N$-dimethylamino)cinnamoyl moiety incorporated per molecule of fully active enzyme.

\section{Comparison of spectra of covalent intermediates formed from DACA and DACI}

The absorption spectra of covalent intermediates derived from both the E1 and E2 isoenzymes were identical, within experimental error, with either DACA or DACI as substrate (see
Table 2. Spectral properties of 4-trans-( $N N$-dimethylamino)cinnamoyl derivatives

Solvents employed: 1, $6.0 \mathrm{M}$-guanidinium chloride/0.1 M-Tris/ $\mathrm{HCl} / 2$ mM-EDTA, pH 7.0; 2, 50 mM-sodium acetate $/ 2.0 \%(\mathrm{w} / \mathrm{v})$ SDS, pH 5.2; 3 , distilled water.

\begin{tabular}{|c|c|c|c|}
\hline Compound & Solvent & $\lambda_{\max .}(\mathrm{nm})$ & $\epsilon\left(\mathrm{mM}^{-1} \cdot \mathrm{cm}^{-1}\right)$ \\
\hline \multicolumn{4}{|l|}{$\begin{array}{l}\text { Covalent intermediates from } \\
\text { enzyme + DACA }\end{array}$} \\
\hline E1 & 1 & 414 & 28 \\
\hline E2 & 1 & 416 & 31 \\
\hline E1 & 2 & 408 & 31 \\
\hline E2 & 2 & 409 & 30 \\
\hline \multicolumn{4}{|l|}{$\begin{array}{l}\text { Covalent intermediates from } \\
\text { enzyme + DACI* }\end{array}$} \\
\hline El & 2 & 406 & $\dagger$ \\
\hline E2 & 2 & 406 & 35 \\
\hline DACA & 3 & 396 & 29 \\
\hline $\mathrm{AACI}$ & 2 & 425 & $22 \ddagger$ \\
\hline $\begin{array}{l}\text { 4-trans-( } N N \text {-Dimethylamino)- } \\
\text { cinnamic acid }\end{array}$ & 3 & 340 & $15^{+}$ \\
\hline $\begin{array}{l}\text { 4-trans-( } N N \text {-Dimethylamino)- } \\
\text { cinnamoyl- } N \text {-acetylcysteine }\end{array}$ & 2 & 405 & $\dagger$ \\
\hline $\begin{array}{l}\text { 4-trans-(NN-Dimethylamino)- } \\
\text { cinnamoyl ethyl ester }\end{array}$ & 1 & 362 & 22 \\
\hline \multicolumn{4}{|c|}{$\begin{array}{l}\text { * Values reported here are each an average of two separate } \\
\text { determinations. } \\
+ \text { These absorption coefficients were not accurately determined. } \\
\ddagger \text { This value is lower than that reported by Breaux \& Bender } \\
\text { (1976), possibly owing to the presence of some } 4 \text {-trans- }(N N \text {-dimethyl- } \\
\text { amino)cinnamic acid as impurity. }\end{array}$} \\
\hline
\end{tabular}

Table 3. Sequence analysis of the $\left.\right|^{3} \mathbf{H} \mid \mathrm{DACA}-$ labelled peptide from the E2 isozyme

The position number in the $\mathrm{E} 2$ isoenzyme is given as a superscript to the amino acid (Hempel et al., 1985). The amount of $\left[{ }^{3} \mathrm{H}\right] \mathrm{DACA}-$ labelled tryptic peptide was $1.2 \mathrm{nmol}$ (calculated from the specific radioactivity before sequencing).

\begin{tabular}{|c|c|c|}
\hline Peptide & $\begin{array}{l}\text { Yield } \\
\text { based on } \\
\text { sequence } \\
\text { (pmol) }\end{array}$ & $\begin{array}{l}\text { Position number and residues identified } \\
\text { (Xaa }=\text { unidentified) }\end{array}$ \\
\hline A & 1000 & $\begin{array}{l}{ }^{273} \text { Ser-Pro-Xaa-Ile-Ile-Met-Ser-Asp-Ala-Asp- } \\
\text { Met-Asp-Trp-Ala-Val-Glu-Gln-His-Ala-Phe- } \\
\text { Ala-Leu-Phe-Phe-Asn-Gln-Gly-Gln-Xaa-Xaa- } \\
\text { Xaa-Ala-Gly-Ser }{ }^{306}\end{array}$ \\
\hline B & 1200 & $\begin{array}{l}{ }^{439} \text { Ala-Asn-Xaa-Leu-Ser-Gln-Ala-Leu-Gln- } \\
\text { Xaa-Gly-Thr-Val-Xaa-Val-Asn-Xaa-Tyr-Val- } \\
\text { Phe-Gly-Xaa-Phe-Gly-Xaa-Gln-Ser-Pro }{ }^{464}\end{array}$ \\
\hline $\mathrm{C}$ & 1200 & $\begin{array}{l}{ }^{156} \text { His-Glu-Pro-Val-Gly-Val-Xaa-Gly-Gln-Ile- } \\
\text { Ile-Pro-Trp-Asn-Phe-Pro-Leu-Leu-Met-Xaa- } \\
\text { Ala-Trp-Lys }\end{array}$ \\
\hline D & 1000 & $\begin{array}{l}{ }^{100} \text { Tyr-Thr-Xaa-Ala-Ala-Leu-Glu-Thr-Xaa- } \\
\text { Asp-Xaa-Xaa-Lys }{ }^{112}\end{array}$ \\
\hline E & 500 & $\begin{array}{l}{ }^{4} \text { Ala-Xaa-Gln-Ala-Val-Xaa-Ala-Pro-Asn-Xaa- } \\
\text { Gln-Pro-Glu-Xaa-Phe-Xaa-Xaa-Xaa-Ile-Phe- } \\
\text { Ile-Asn-Xaa-Glu-Trp }{ }^{28}\end{array}$ \\
\hline
\end{tabular}

Fig. 1). The absorbance maxima and determined absorption coefficients for covalent intermediates and some model compounds are shown in Table 2 . Strict comparison of absorbance maxima is only valid under identical conditions, since the maxima 
are influenced by solvents. The absorbance maxima of covalent intermediates from DACA and DACI with both E1 and E2 isoenzymes were identical within the experimental error of the procedure employed. Both resembled that of DACA and of 4-trans-( $N N$-dimethylamino)cinnamoyl- $N$-acetylcysteine, and differed considerably from those of 4-trans-( $N N$-dimethylamino)cinnamoyl ethyl ester and 4-trans-( $N N$-dimethylamino)cinnamic acid.

\section{Partial purification and sequence analysis of the $\left[{ }^{3} \mathrm{H}\right] \mathrm{DACA}-$ labelled peptide of the $\mathrm{E} 2$ isoenzyme}

Although the stability of the covalent intermediate was better than expected, the number of steps required for purification to homogeneity reduced the yield of labelled peptide to the point where label localization was impossible. This necessitated the alternate approach of sequencing partially purified peptides. The $\left[{ }^{3} \mathrm{H}\right]$ DACA-labelled E2 isoenzyme, after tryptic digestion, was chromatographed on the Mono P column and eluted with $1 \mathrm{M}$ acetic acid as a single sharp peak. Labelled material precipitated when the $\mathrm{pH}$ was adjusted to $\sim 6.5$; the precipitate $(1.2 \mathrm{nmol})$ was washed, dissolved in $0.1 \%$ TFA ( $/ \mathrm{v}$ in water), and sequenced. Protein sequencing identified a mixture of five peptides (see Table 3), A, B, C, D, and E, corresponding to residues $273-306,439-464,156-178,100-112$, and 4-28 respectively. The initial yields from the first cycle of sequencing of peptides A-D all corresponded to the amount of $\left[{ }^{3} \mathrm{H}\right]$ DACAlabelled peptide (calculated before sequencing from the amount of radioactive label); that of peptide $\mathrm{E}$ was about $50 \%$ less. By cycle 28 , peptides $C$ and $D$ were completely sequenced, and peptides $\mathrm{B}$ and $\mathrm{E}$ were no longer detectable; only peptide $\mathrm{A}$ remained. No significant amount of radioactivity was detected in cycles 1-28 (Fig. 2); a large increase in radioactivity was observed in cycles 29-31, with the highest amount in cycle 29 (corresponding to cysteine-301 in aldehyde dehydrogenase). Purification and sequence analysis of the $\left[{ }^{3} \mathrm{H}\right] \mathrm{DACA}$-labelled peptide from the E2 isoenzyme was repeated twice. In expt. 2, the tryptic hydrolysate was chromatographed on a Pharmacia Superose 12 gel-filtration column equilibrated in $0.15 \mathrm{M}$-ammonium bicarbonate (Loomes et al., 1990). Labelled fractions were combined and applied to a Waters $\mathrm{C}_{18}$ column equilibrated in $0.1 \%$ TFA. Radioactive material was eluted at 26, 28, 30, and $39 \mathrm{~min}$, with an 80 min linear gradient to $100 \%$ methanol. The peak eluted at 39 min was further purified on a Supelco $\mathrm{C}_{8}$ column equilibrated in $0.1 \%$ TFA, and eluted as a single peak at $15.5 \mathrm{~min}$ with a 40 min linear gradient to $100 \%$ acetonitrile, and sequenced. In expt. 2, the greatest amount of radioactivity also corresponded to cysteine-301. In expt. 3, the labelled material was eluted from the Mono P column with $1 \mathrm{M}$-acetic acid. The precipitation step was omitted; further purification employed two additional steps on a Supelco $\mathrm{C}_{4}$ column. In the first step, a 40 min linear gradient from $0.1 \%$ TFA to $100 \%$ methanol was used (a single radioactive peak was obtained at 19-20 min); and, in the second step, a 40 min linear gradient from $0.1 \%$ TFA to acetonitrile was used (the radioactivity was eluted as a single peak at $17 \mathrm{~min}$ ). In expt. 3 the greatest amount of radioactive label corresponded to cysteine- 302 and -303 .

It can be seen from distribution of radioactivity in Fig. 2 that the label is not stable to sequencing conditions. A comparison of the amounts of derivatized cysteine in cycles that contained the most label showed that decomposition occurred during sequencing. Thus the amount of derivatized cysteine in cycle 29 (Fig. 2), about $20 \mathrm{pmol}$ as calculated from radioactivity, was much lower $(\sim 10 \%)$ than the estimated amount of amino acid $(\sim 200 \mathrm{pmol}$ estimated from repetitive yield). In the other two experiments this comparison indicated a 'label yield' of $17 \%$ and $2 \%$ for expts. 2 and 3 respectively.

\section{Purification of labelled tryptic peptides from [ $\left.{ }^{3} \mathrm{H}\right] \mathrm{DACI}$-labelled E2 isoenzyme and $\boldsymbol{N}$-terminal sequence analysis}

Chromatography on the diphenyl reverse-phase column (see the Materials and methods section) separated the labelled material into two species: one peak in fractions 12.5-14.0 and another in fractions 15.0-17.5. Material from fractions 12.5-14.0 was purified to near-homogeneity (see Table 4), and identified by sequence analysis as the tryptic peptide spanning from residues 273-307 of the primary structure of the E2 enzyme. This peptide was sequenced in its entirety; the initial yield of the peptide was estimated to be $\sim 600-650$ pmol from sequence analysis; that calculated from radioactivity was 540 pmol. Wash liquid from the sequencer was found to contain $48.5 \%$, and the sample disc and Teflon seal of the sequencer contained only $1.6 \%$ and $1.1 \%$ of the original radioactivity respectively, indicating that decomposition had occurred. No significant levels of radioactivity were associated with any of the sequencing cycle fractions, although radioactivity was above background in all fractions. When material from fractions $15.0-17.5$ was sequenced, a peptide beginning at residue 273 was identified as a minor component (Table 4). The amount of sample calculated to be present, based upon radioactivity, correlated best with this peptide, but there was insufficient material to obtain the entire sequence (sequencing was not continued past 14 cycles). Since this peptide eluted from the reverse-phase h.p.l.c. column at a later retention time than the first material purified, it appears likely that it was a partial cleavage product.

\section{Pronase digestion of covalent intermediate formed from E2 isoenzyme and $\left[{ }^{3} \mathrm{H}\right] \mathrm{DACI}$}

The precipitated E2-DACI adduct was subjected to Pronase digestion (see Table 5). The digested enzyme was applied to a $C_{18}$ $\mu$ Bondapak reverse-phase column and eluted with a gradient of $0.1 \%$ TFA to $100 \%$ methanol $(80 \mathrm{~min}$, linear gradient, flow rate of $1.5 \mathrm{ml} / \mathrm{min}$ ). A major peak of radioactivity was observed in fractions 37-38, which were eluted in a position distinct from that of DACA or the corresponding acid. DACI itself is acidlabile and decomposed under similar conditions of chromatography. Since Pronase has esterase activity and could have potentially hydrolysed the covalent intermediate, the time course of Pronase digestion was investigated over a period of $5-18 \mathrm{~h}$ by chromatography on a $\mathrm{C}_{18} \mu$ Bondapak column. It was found that labelled material in fractions 37-38 occurred at a maximal level at about 12-14 h. After Pronase digestion for $14 \mathrm{~h}$, fraction 38, which contained the most label, was analysed for amino acid composition, as were side fractions (36 and 39). Aliquots were freeze-dried and subjected to hydrolysis with $\mathrm{HCl}$ with or without prior treatment with performic acid. Cysteic acid found in fraction 38 after performic acid oxidation was at the level expected from the specific radioactivity of the label (Table 5); side fractions which contained no radioactivity did not contain measurable amounts of cysteine. Other amino acids were found at low levels and/or were also present in side fractions. Results of analyses after $\mathrm{HCl}$ hydrolysis alone were comparable with those obtained where performic acid treatment was carried out, indicating no significant destruction of amino acids during oxidation. Pronase digestion was repeated, and the labelled material eluted from the $C_{18}$ column was further purified by chromatography on a diphenyl-bonded reverse-phase column. Analysis of this material gave the same results (Table 5).

\section{Pronase digestion of covalent intermediate from E2 isoenzyme and DACA}

In a similar experiment, the $\mathrm{E} 2$ isoenzyme was modified with

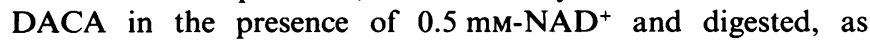




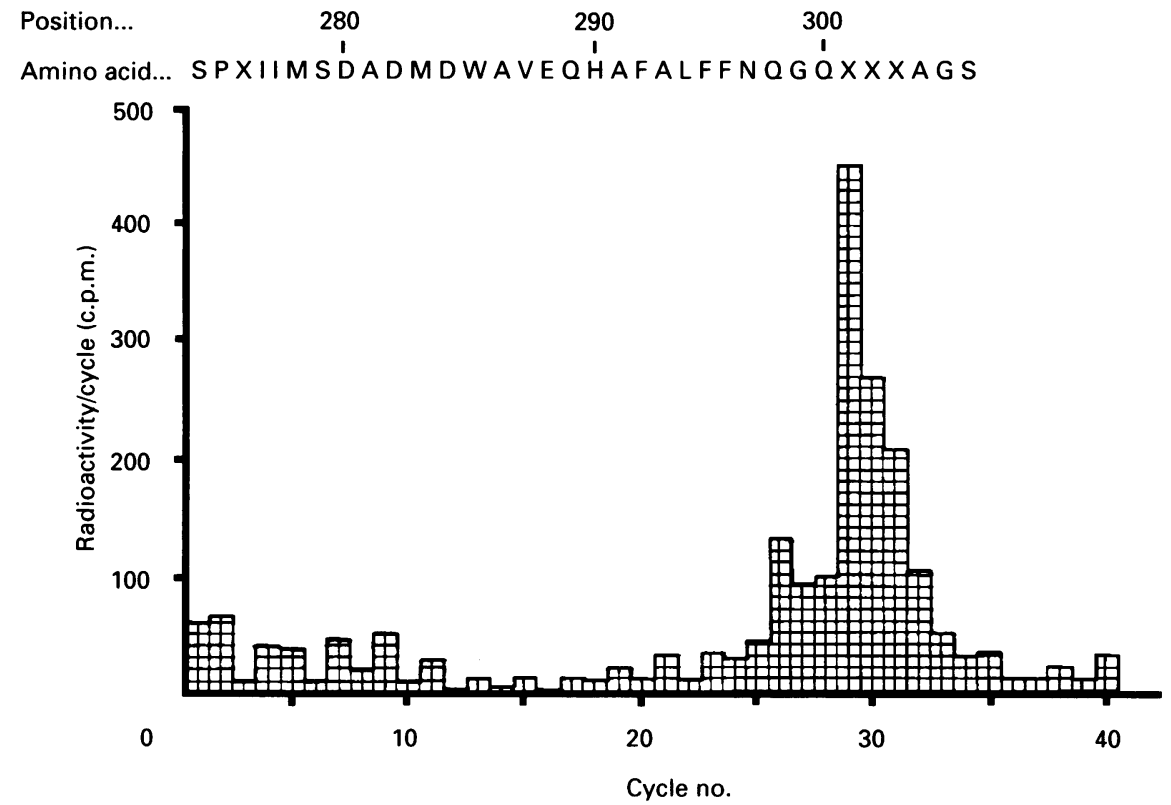

Fig. 2. Radioactivity profile obtained by sequencing the labelled peptide of the $\mathbf{E 2}$ isoenzyme

The radioactivity is plotted against the cycle number; also shown, in single-letter code, are the corresponding amino acids and their positions in the primary structure $(\mathrm{X}=$ unidentified $)$.

Table 4. Sequence analysis of the $\left[^{3} \mathrm{H} \mid \mathrm{DACI}-\right.$ labelled peptide from the E2 isoenzyme

Unidentified amino acids are shown as 'Xaa'.

\begin{tabular}{|c|c|c|c|}
\hline Peptide material & $\begin{array}{l}\text { Amount applied (based on } \\
\text { reagent specific radioactivity; } \\
\text { pmol) }\end{array}$ & $\begin{array}{l}\text { Yield based on sequence } \\
\qquad(\mathrm{pmol})\end{array}$ & Peptide present \\
\hline $\begin{array}{l}\text { Fractions } 12.5-14.0 \text { from the } \\
\text { diphenyl column* }\end{array}$ & 540 & $600-650$ & $\begin{array}{l}\text { Ser-Pro-Asn-Ile-Ile-Met-Ser-Asp-Ala-Asp-Met- } \\
\text { Asp-Trp-Ala-Val-Glu-Gln-Ala-His-Phe-Ala- } \\
\text { Leu-Phe-Phe-Asn-Gln-Gly-Gln-Xaa-Xaa-Xaa- } \\
\text { Ala-Gly-Ser-Arg (corresponding to residues } \\
\text { 273-307 of the primary structure) } \\
\text { Gln-Ile-Ile-Pro-Trp-Asn-Phe-Pro-Leu-Leu } \\
\text { (starting in ninth cycle of sequencing; } \\
\text { corresponding to residues } 164-173 \text { of the } \\
\text { primary structure of the E2 enzyme) }\end{array}$ \\
\hline $\begin{array}{l}\text { Fractions } 15.0-17.5 \text { from the } \\
\text { diphenyl column } \dagger\end{array}$ & 35 & $\begin{array}{l}1130 \\
300 \\
15-20\end{array}$ & $\begin{array}{l}\text { His-Glu-Pro-Val-Gly-Val-Xaa-Gly-Gln-Ile-Ile- } \\
\text { Pro-Trp-Asn (corresponding to residues } \\
156-169 \text { of the primary structure) } \\
\text { Ala-Asn-Tyr-Leu-Ser-Gln-Ala-Leu-Gln-Ala-Gly- } \\
\text { Thr-Val-Trp (corresponding to residues } \\
439-452 \text { of the primary structure) } \\
\text { Ser-Pro-Asn-Ile-Ile-Met-Ser (corresponding to } \\
\text { residues } 273-279 \text { of the primary structure; } \\
\text { very low yield prevented further identification) }\end{array}$ \\
\hline
\end{tabular}

described above, with Pronase. The labelled material was detected in the same position of elution from the $\mu$ Bondapak column as that from DACI, and was purified by the same procedure and analysed. In addition, the spectral properties of the labelled material were monitored throughout the experiment up to the stage of amino acid analysis. The spectrum remained unchanged during chromatography, with the absorbance maximum at $412-415 \mathrm{~nm}$. After the second reverse-phase chromatography step, an aliquot of each of the two fractions containing the largest amount of radioactivity were analysed for amino acid composition (Table 5). Results were the same as those obtained with the labelled material from reaction of the enzyme with DACI.

Effect of cysteine-302 carboxyamidation on the reaction of DACA and DACI with E1 isoenzyme

Cysteine-302 can be specifically labelled in the E1 isoenzyme by iodoacetamide (Hempel et al., 1982a; Blatter, 1990). The 
Table 5. Amino-acid-composition analysis of Pronase digests

The covalent intermediate (obtained in the presence of $0.5 \mathrm{~mm}$ $\mathrm{NAD}^{+}$, for DACA), dissolved in guanidinium chloride, was dialysed into $0.1 \mathrm{M}$-ammonium bicarbonate for digestion with Pronase. Pronase stock solutions were freshly prepared in $50 \mathrm{~mm}-\mathrm{Tris} / \mathrm{HCl}$, $\mathrm{pH} 6.5$, at a concentration of $10 \mathrm{mg} / \mathrm{ml}$, and Pronase was added to a final concentration of $4.0 \%(\mathrm{w} / \mathrm{w})$. Pronase digestions were allowed to proceed for about $12-14 \mathrm{~h}$ at $37^{\circ} \mathrm{C}$.

\section{Compound}

used to form

covalent

intermediate

with E2

isoenzyme

$\begin{array}{cc}\begin{array}{c}\text { Amount of } \\ \text { peptide/amino } \\ \text { acid material } \\ \text { obtained (nmol)* }\end{array} & \begin{array}{c}\text { Amount of } \\ \text { cysteic acid } \\ \text { detected } \\ (\mathrm{nmol}) \dagger\end{array}\end{array}$

Levels of other amino acids

DACI

0.83

1.01

Gly and Pro at

levels of

$0.20 \mathrm{nmol}$ each;

Met present at

0.18 nmol. $\ddagger$ All

others at

$\leqslant 0.11 \mathrm{nmol}$.

DACI $\quad 0.65 \quad 0.74 \quad \begin{gathered}\text { Other amino acids } \\ \text { at a level of }\end{gathered}$

$\leqslant 0.15 \mathrm{nmol}$.

$\begin{array}{llll}\text { DACA } & 0.27 & 0.34 & \text { Other amino }\end{array}$

acids at

$\leqslant 0.08 \mathrm{nmol}$.

* Based upon the specific radioactivity of the radiolabelled reagent.

$\dagger$ From amino-acid-composition analysis.

$\ddagger$ Gly and Pro were present at comparable levels in adjacent fractions, where the level of radioactivity detected was near background. Met levels were $\sim 0.09 \mathrm{nmol}$ in adjacent fractions as well. Fractions from this elution were analysed for amino acid composition, giving similar results (Table 3). Scintillation counting of the fractions eluted during the $\mathrm{HCl}-$ hydrolysed and unhydrolysed (derivatized blank) sample gradients showed no significant peaks of radioactivity correlating with any phase of the gradient.

effects of this modification on the formation of the covalent intermediate were tested. The $\mathrm{E} 1$ isoenzyme $(4.6 \mu \mathrm{M})$ was incubated with $100 \mu \mathrm{M}$-iodoacetamide in the presence of $1.5 \mu \mathrm{M}$ $\mathrm{NAD}^{+}$in a total volume of $4 \mathrm{ml}$ at $\mathrm{pH}$ 7.0. A control was incubated in the absence of iodoacetamide. After gel filtration, $\mathrm{NAD}^{+}$and DACA or DACI were added to each sample and, after incubation for $100 \mathrm{~s}$, the protein was precipitated and washed with water. The control reaction mixtures had a distinct yellow colour and gave a characteristic spectrum, whereas the iodoacetamide-modified protein samples remained colourless and showed no spectrum, indicating that iodoacetamide modification prevented formation of the covalent intermediates from both DACA and DACI.

\section{DISCUSSION}

The results presented (Table 1) demonstrate that DACA and DACI are substrates for human liver aldehyde dehydrogenase. Analogously to serine proteinases (Breaux \& Bender, 1976), the enzyme can hydrolyse amides as well as esters. The fact that the stoichiometry of DACA and DACI incorporation was proportional to the amount of catalytically active enzyme, and also that, at saturation (concentrations of substrate $\sim 20 \mu \mathrm{M}$ at completion of the reaction), full active-site occupation was achieved, is in accordance with expectations from MichaelisMenten kinetics. Further testing of incorporation specificity, however, was especially important in the case of DACA, which bears an aldehyde group that is reactive with thiol group, of which 36-44 are present per molecule of human aldehyde dehydrogenase. It was observed that the formation of a trichloroacetic acid-stable DACA adduct occurred only in the presence of $\mathrm{NAD}^{+}$. Since $\mathrm{NAD}^{+}$is required for dehydrogenation of DACA to occur at the active site, the results were suggestive of the reaction occurring at that site. DACI is easily hydrolysable and its hydrolysis can be catalysed by $\mathrm{SH}$ groups. $\mathrm{NAD}^{+}$is not essential for ester hydrolysis by aldehyde dehydrogenase and as such could not be used as a control for DACI. To test whether the reaction with DACA and DACI occurred at the active site both were allowed to react with aldehyde dehydrogenase in the presence of $\mathrm{NAD}^{+}$and chloral; the latter is an aldehydesubstrate-competitive inhibitor that also inhibits the esterase reaction. The effect of chloral hydrate on formation of covalent intermediate (shown in Fig. 1) demonstrates almost complete protection of chloral hydrate against formation of an intermediate from both DACA and DACI, suggesting strongly that only the active site of aldehyde dehydrogenase is involved in the reaction with both compounds.

The spectral properties of the covalent intermediates formed from the E1 and E2 isoenzymes and DACI were identical (within experimental error) with those of the covalent intermediates from DACA (Table 2). They resemble those of 4-trans- $(N N$ dimethylamino)cinnamoyl thioesters and of 4-trans- $(\mathrm{NN}$ dimethylamino)cinnamoylimidazoles, but not those of the analogous oxygen esters or acids. Although the absorbance spectra of the covalent intermediates also resemble that of DACI, the possibility of reaction with histidine seems unlikely, since the DACI substrate itself is unstable to conditions of h.p.l.c., whereas the covalent intermediates were stable. The spectral properties were totally inconsistent with a covalent intermediate being formed with a hydroxy group (Loomes et al., 1990).

Employing the E2-DACA derivative, the peptide corresponding to residues 273-307 was identified in three separate experiments, each using a different purification scheme. The peptide identified by Loomes et al. (1990), comprising residues 68-77 (or any part of it) was not detected in any peptide mixture containing the label-bearing peptide derived from the E2 isoenzyme. Identification was the most unequivocal in the first experiment, since all impurities were shorter and sequenced out. In all experiments, the radioactive label was associated with residues 301-303. The first tryptic peptide from the E2-DACI derivative was identified by sequencing, as also was that comprising amino acid residues 273-307 of the primary structure (Table 4). During sequencing of the second peptide, the radioactivity present in the sample correlated best with the same peptide (starting at residue 273), which was, however, contaminated with large amounts of other peptides. The peptide containing cysteine-162, which was postulated by Tu \& Weiner (1988b) to be involved in ester hydrolysis, was a major component of the second peptide mixture (Table 4), where it was present in amounts 30 times higher than that expected from the radioactive label. Thus, from our results, it appears unlikely that cysteine- 162 could possibly participate in ester hydrolysis.

Further experiments involved digestion of the covalent intermediate derived from the E2 enzyme and DACA and DACI with Pronase. After digestion and chromatography, radioactively labelled material from both derivatives, when analysed for amino acid composition, was found to contain only cysteine in the amount expected from the specific radioactivity of the label (Table 5) and to retain absorbance in the region of $412-415 \mathrm{~nm}$ up to the stage of amino-acid-composition analysis. These results are also totally inconsistent with the report of Loomes et al. (1990), but are in agreement with those of Kitson et al. (1991).

Thus, by these experiments, participation of cysteine located 
on the tryptic peptide comprising residues $273-307$ in the aldehyde dehydrogenase catalytic mechanism is established, in both aldehyde dehydrogenation and ester hydrolysis. The peptide from the E2 isoenzyme bearing the label from DACA or DACI contains three cysteine residues (at positions 301-303). Label localization within these three residues was difficult (Fig. 2), because the adduct was unstable to sequencing conditions. Even with stable derivatives, label localization is generally hampered by a 'preview' and 'lag' of radioactivity before and after the actual peak. Because of difficulty in pinpointing the exact label position, the E1 isoenzyme modified at cysteine-302 with iodoacetamide was tested for covalent intermediate formation. No covalent intermediate was formed, suggesting that cysteine-302 was the residue involved in its formation. Cysteine- 302 is also the only cysteine residue conserved in all aldehyde dehydrogenases so far sequenced (Lindahl \& Hempel, 1990). Thus cysteine-302 is the amino acid residue which participates in the formation of the covalent intermediate with both the aldehyde and ester substrates.

This work was supported by U.S. Public Health Service National Institute on Alcohol Abuse and Alcoholism Grant AA00186, Research Scientist Award K05AA00046 and the Charles and Jonanna Busch Memorial Fund. This work was carried out by E. E. B. (aldehyde dehydrogenation) and D. P. A. (ester hydrolysis) in partial fulfilment of the requirements for a Ph.D. degree at Rutgers University.

\section{REFERENCES}

Abriola, D. P., Fields, R., Stein, S., MacKerell, A. D., Jr. \& Pietruszko, R. (1987) Biochemistry 26, 5679-5684

Abriola, D. P., MacKerell, A. D., Jr. \& Pietruszko, R. (1990) Biochem. J. 266, 179-187

Blatter, E. E. (1990) Ph.D. Dissertation, Rutgers University (Dissert. Abstr. Int. B51, 3358; University Microfilms no. DA9034880)

Blatter, E. E., Tasayco, J. M. L., Prestwich, G. \& Pietruszko, R. (1990) Biochem. J. 272, 351-358

Breaux, E. J. \& Bender, M. L. (1976) Biochem. Biophys. Res. Commun. 70, 235-240

Buckley, P. D. \& Dunn, M. F. (1982) Enzymol. Carbonyl Metab. 23-35
Buckley, P. D. \& Dunn, M. F. (1985) Enzymol. Carbonyl Metab. 2, 15-27

Deady, L. W., Buckley, P. D., Bennett, A. F. \& Blackwell, L. F. (1985) Arch. Biochem. Biophys. 243, 586-597

Duncan, R. J. S. (1979) Biochem. J. 183, 459-462

Duncan, R. J. S. (1985) Biochem. J. 230, 261-267

Greenfield, N. J. \& Pietruszko, R. (1977) Biochim. Biophys. Acta 483, $35-45$

Grunwell, J. R. \& Foerst, D. L. (1976) Synth. Commun. 6, 453-455

Heinrikson, R. L. \& Meredith, S. C. (1984) Anal. Biochem. 136, 65-74

Hempel, J. D. (1981) Ph.D. Dissertation, Rutgers University (Dissert. Abstr. Int. B42, 3664; University Microfilms no. DA80204216)

Hempel, J. D. \& Pietruszko, R. (1981) J. Biol. Chem. 256, 10889-10896

Hempel, J. D., Pietruszko, R., Fietzek, P. \& Jörnvall, H. (1982a) Biochemistry 21, 6834-6838

Hempel, J. D., Reed, D. M. \& Pietruszko, R. (1982b) Alcohol. Clin. Exp. Res. 6, 417-425

Hempel, J. D., von Bahr-Lindstrom, H. \& Jörnvall, H. (1984) Eur. J. Biochem. 141, 21-35

Hempel, J., Kaiser, R. \& Jörnvall, H. (1985) Eur. J. Biochem. 153, 13-28

Hoffman, S. J., Chu, S. S.-T., Lee, H., Kaiser, E. T. \& Carey, P. R. (1983) J. Am. Chem. Soc. 105, 6971-6973

Jakoby, W. B. (1963) Enzymes 2nd Ed. 7, 203-221

Kitson, T. M. (1978) Biochem. J. 175, 83-90

Kitson, T. M., Hill, J. P. \& Midwinter, G. G. (1991) Biochem. J. 275, 207-210

Lindahl, R. \& Hempel, J. (1990) Enzymol. Mol. Biol. Carbonyl Metab. $3,1-8$

Liu, T.-Y. \& Boykins, R. A. (1989) Anal. Biochem. 182, 383-387

Loomes, K. M. \& Kitson, T. M. (1986) Biochem. J. 238, 617-619

Loomes, K. M., Midwinter, G. G., Blackwell, L. F. \& Buckley, P. D. (1990) Biochemistry 29, 2070-2075

MacGibbon, A. K. H., Haylock, S. J., Buckley, P. D. \& Blackwell, L. F. (1978) Biochem. J. 171, 533-548

MacKerell, A. D., Jr., MacWright, R. S. \& Pietruszko, R. (1986) Biochemistry 25, 5182-5189

Pfeiffer, P. \& Haefelin, G. (1922) Ber. Dtsch. Chem. Ges. 55, 1769-1788

Tu, G.-C. \& Weiner, H. (1988a) J. Biol. Chem. 263, 1212-1217

Tu, G.-C. \& Weiner, H. (1988b) J. Biol. Chem. 263, 1218-1222

von Bahr-Lindstrom, H., Jeck, R., Woenckhaus, C., Sohn, S., Hempel, J. \& Jörnvall, H. (1985) Biochemistry 24, 5847-5851

Weber, J. A., Turpin, P.-Y., Bernhard, S. A. \& Peticolas, W. L. (1986) Biochemistry 25, 1912-1917

Yun, S.-L. \& Suelter, C. H. (1977) Biochim. Biophys. Acta 489, 1-13

Received 27 June 1991/4 September 1991; accepted 9 September 1991 